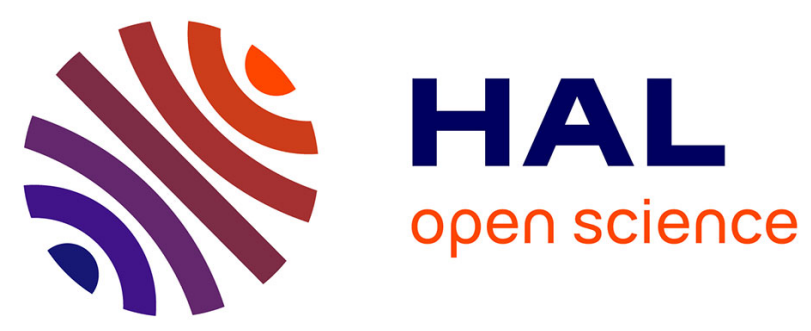

\title{
Do Korean L2 learners have a "foreign accent" when they speak French? Production and perception experiments on rhythm and intonation
}

Bénédicte Grandon, Hiyon Yoo

\section{- To cite this version:}

Bénédicte Grandon, Hiyon Yoo. Do Korean L2 learners have a "foreign accent" when they speak French? Production and perception experiments on rhythm and intonation. 7th international conference on Speech Prosody, May 2014, Dublin, Ireland. hal-01080024

\section{HAL Id: hal-01080024 \\ https://hal.science/hal-01080024}

Submitted on 4 Nov 2014

HAL is a multi-disciplinary open access archive for the deposit and dissemination of scientific research documents, whether they are published or not. The documents may come from teaching and research institutions in France or abroad, or from public or private research centers.
L'archive ouverte pluridisciplinaire HAL, est destinée au dépôt et à la diffusion de documents scientifiques de niveau recherche, publiés ou non, émanant des établissements d'enseignement et de recherche français ou étrangers, des laboratoires publics ou privés. 


\title{
Do Korean L2 learners have a "foreign accent" when they speak French? Production and perception experiments on rhythm and intonation
}

\author{
Bénédicte Grandon, Hiyon Yoo \\ Laboratoire de Linguistique Formelle, Labex - EFL, Université Paris Diderot
b_grandon@yahoo.fr, yoo@linguist.univ-paris-diderot.fr
}

\begin{abstract}
French and Korean are two languages with similar prosodic characteristics as far as rhythm and intonation are concerned. In this paper, we present the results of production and perception tests where we describe the prosodic characteristics of Korean L2 learners of French. Our aim is to analyze the impression of "foreign accent" for two prosodic components (intonation and rhythm) of speech produced by Korean L2 learners of French and the perception of this "accent" by native listeners of French (L1). We show that the productions of Korean learners and French native speakers present minor differences but that they do no translate into cues for determining clearly the presence of a "foreign accent".

Index Terms: L2 prosody, intonation, rhythm, production, perception, Korean, French
\end{abstract}

\section{Introduction}

Through the past decades, several second language (L2) acquisition models have shown that similarity is more problematic than difference for the L2 learner. Researchers, among others [1], in his Speech Learning Model but also [2] and [3] for intonation and [4] for rhythm, posit that L2 acquisition is more difficult for sounds and prosodic units where the contrast with L1 is poor. What happens then when L1 and L2 share most prosodic characteristics? In this paper, we investigate the impression of "foreign accent" (i.e. nonnative production, see among others [5] and [6]) for two prosodic components (intonation and rhythm) in speech produced by Korean L2 learners of French and the perception of this "accent" by native listeners of French (L1).

French and Korean are both described as "syllable-timed" languages ([7] for French, [8] for Korean), with common prosodic features: (1) Primary stress, realized through syllabic lengthening, is located on the last syllable of the last lexical word of a phrase (among others [9] and ([7] for French, [8] for Korean), (2) non-stressed syllables have a constant duration ([7] for French, [10] for Korean), and (3) declarative utterances have a falling pitch contour beginning on the first accented syllable in French [7] and on the utterance's second syllable in Korean [10] and continuing through the end of the sentence. Furthermore, the intonation of modality is seen as the result of the realization of the fundamental frequency (F0) at the end of utterances both in French ([11], [9]) and Korean ([8]). Finally, the declination slope is steadily declining in both languages, no matter the length of the utterances ([12] for Korean and [13] for French).

Since French and Korean share these prosodic characteristics, we expect that (1) French native speakers and Korean learners of French (L2) produce overall similar intonational and durational patterns of vowels at the end of chunks and (2) that these similarities, along with minor differences in the production of Korean speakers cannot be perceived as the manifestations of a "foreign accent". In the next sections, we present the production and perception analyses we conducted to test these hypotheses.

\section{Rhythm and intonation in L2 Korean productions of French utterances}

In order to determine the prosodic proximity between French L1 and L2 productions, we built a comparative reading experiment with L2 learners of French and French native speakers. The aim of this experiment is to locate the prosodic differences concerning intonational patterns and rhythmic organization that can be seen in L2 productions and to measure variation from native $\mathrm{L} 1$ productions.

\subsection{Corpus and experimental procedure}

The corpus consisted in declarative utterances following the pattern "NP subject $^{-V}-\mathrm{NP}_{\text {Object", where each chunk has an }}$ identical number of syllables (varying from 1 to 10 syllables). Three examples (from the shorter to the longest utterance) are given below in French, with English translation:

\section{(1) utterance $1 \times 3$ ( 9 syllables)}

(Barbara) $)_{\mathrm{SuBJ}}(\text { a perdu })_{\mathrm{V}}$ (son vélo $)_{\mathrm{OBJ}}$

(Barbara) $_{S U B J}(\text { lost })_{V}$ (her bike $)_{O B J}$

(2) utterance $5 \times 3$ (15 syllables)

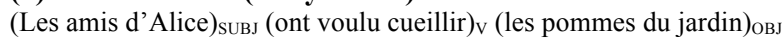

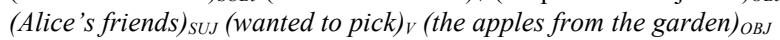
(3) utterance 10x3 (30 syllables)

(La voisine de ma cousine Annabelle) SuBj $_{\text {(a vraiment dû hésiter à }}$

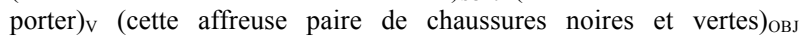
(The neighbour of my cousin Annabelle) SUBJ $_{\text {(must really have }}$

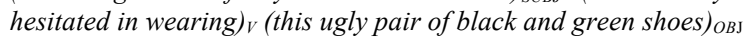

Two female native speakers of Standard French and four native speakers of Standard Seoul Korean (three female and one male), with variable proficiency levels in French were asked to read the sentences that were presented to them. All speakers were students in their twenties living in Seoul at the time of the recordings. The corpus gathers a total of 20 utterances presented five times in a random order and mixed with distractors that were not taken into account (a total of 600 utterances were analyzed).

The recordings took place in a quiet room, using the Audacity software [14] (in mono, using a sampling frequency of 22050 $\mathrm{Hz}$ ad 32bits) on a laptop, with an external microphone. Annotations of the sentences and extraction of durations and F0 values were done first automatically with the Easyalign software [15] and Praat scripts [16], and then checked manually.

Three acoustic parameters were analyzed: rhythm, intonation patterns and declination. For better objectivity in the normalization of the data, we chose the vowel over the syllable as the unit of analysis; thus for rhythm, we used a ratio of the duration of each occurrence produced by the speaker divided by the mean duration of the corresponding vowel in all her/his productions, which allowed us to eliminate both "interspeaker" (resulting from speakers' different speech rates) and 
"intra-speaker" (resulting from different intrinsic vocalic duration) variations, as well as variation resulting from different syllabic structures. For intonation, F0 raw values (three measures per vowel) were converted into semi-tones relative to each speaker's mean $\mathrm{F} 0{ }^{1}$.

The R software [17] was used to run the ANOVA tests.

\subsection{Results and discussion ${ }^{2}$}

\subsubsection{Rhythm}

For the final vowel of each chunk (subject, verb and object), we considered that a vowel is lengthened when its normalized duration is 1.2 or above (mean $+20 \%$ ). We considered that choosing the mean value was not sufficient enough to determine a lengthening compared to the threshold of 1.2, above which lengthening can clearly be perceived

Figure 1 shows the variation of mean vocalic durations for the two groups of speakers (French L1 and Korean L2) for three sentences $(3 \times 3=9,3 \times 5=15$ and $3 \times 10=30$ syllables $)$.

In most cases, both French L1 speakers and Korean L2 learners lengthen the last vowel of the subject chunk. French speakers almost never lengthen the end of a verb, which shows that they tend to group the verb with its object and to place lengthening only at the end of the sentence. Korean speakers present more diverse results, with vocalic lengthening found in six cases out of ten (sentences with $3 \times 4,3 \times 5,3 \times 6,3 \times 7,3 \times 8$, $3 \times 10$ syllables), which might correspond to a more frequent segmentation of the utterance for learners than for native speakers. Vowels at the end of object chunks (which represents also the end of utterances) are systematically longer for French speakers while Korean learners do not produce this expected lengthening (vocalic lengthening of 1,2 can be seen only for sentences with $3 \times 2,3 \times 4$ and $3 \times 10$ syllables).

We ran ANOVA tests to compare the realizations of vowels at the end of chunks for the two groups of speakers. Thus, for sentence $3 \times 3$ syllables, it appears that the third and the ninth vowels produced by French speakers is longer than the adjacent vowels, even though the normalized values never cross the threshold of 1,2. Results of ANOVA tests show a significant difference for both groups, except for the utterancefinal vowel $(\mathrm{F}(1,56)=5,737 \mathrm{p}=.0199)$.

The durations of $3 \times 5$ syllable utterances, are similar for both groups of speakers: both groups lengthen the $5^{\text {th }}$ and the $15^{\text {th }}$ vowels (for this last vowel, the lengthening is much more important for French speakers than for Korean learners), while the $10^{\text {th }}$ vowel is lengthened only by Korean speakers. Notice that the ANOVA test is significant between the two groups only for the $10^{\text {th }}$ syllable $(\mathrm{F}(1,50)=14,657 \mathrm{p}=.0004)$.

For the $3 \times 10$ syllable utterances, there is a lengthening of the $10^{\text {th }}, 15^{\text {th }}$ and $30^{\text {th }}$ vowels for French speakers and of the $3^{\text {rd }}$, $10^{\text {th }}, 16^{\text {th }}, 20^{\text {th }}$ and $30^{\text {th }}$ vowels for Korean speakers. The differences between the two groups are significant for the $10^{\text {th }}$ vowel $(\mathrm{F}(1,51)=5,666 \mathrm{p}=.0211)$ and for the $30^{\text {th }}$ vowel $(\mathrm{F}(1,51)=9,16 \mathrm{p}=.0039)$ but not for the $20^{\text {th }}$ vowel $(\mathrm{F}(1,51)=$ $0,866, \mathrm{p}=.3565)$.

1 We used the following formula taken in [9] for the computation of semi tones:

$\mathrm{F} 0(\mathrm{ST})=12 *(\log (\mathrm{F} 0 /$ speaker's meanF0 $)) / \log (2.00)$

2 ANOVA tests were conducted for every type of sentences, but because of limits of space, we show the results for three utterances, illustrating our purpose.
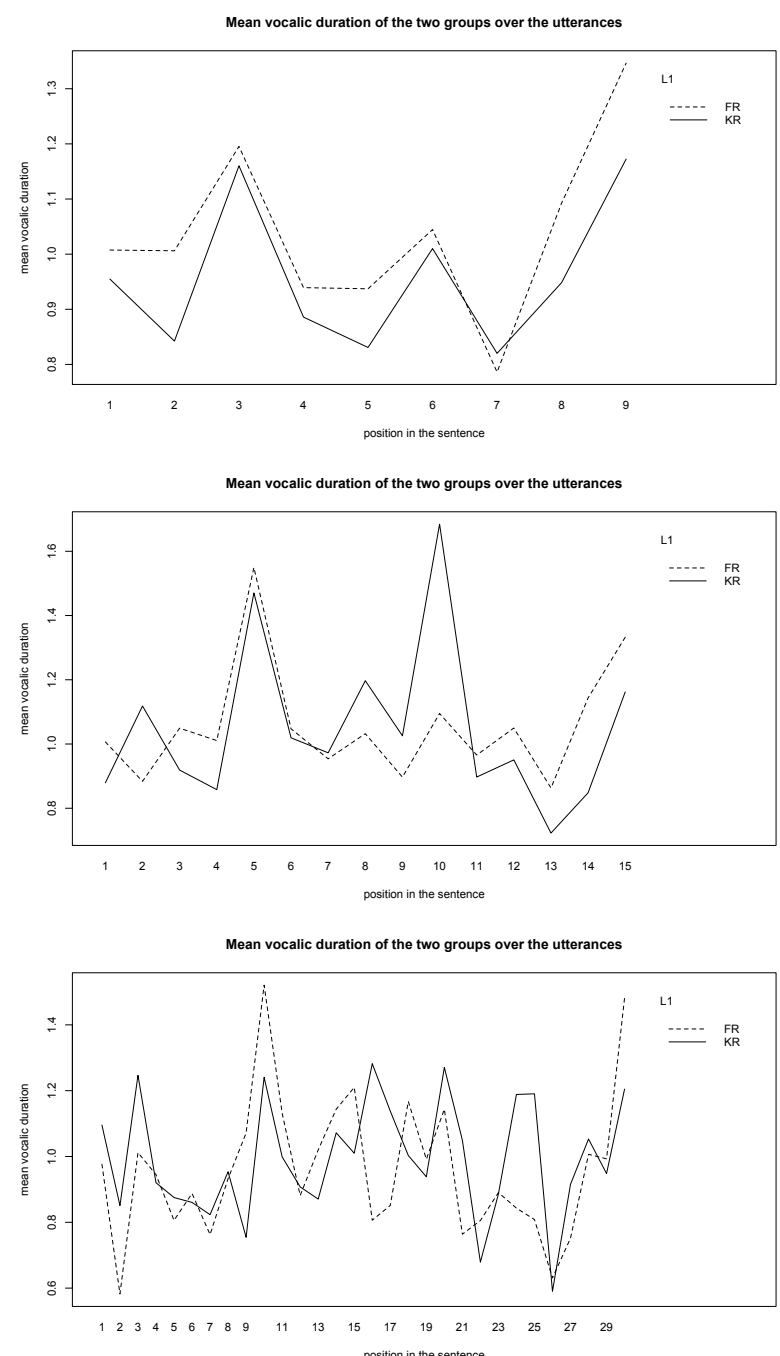

Figure 1: Mean vocalic duration of the two groups for $3 \times 3$, $3 \times 5$ and $3 \times 10$ syllable utterances.

Results show a main difference between the two groups for the final vowel of the utterance, which is lengthened systematically by French speakers while Korean speakers present less homogeneous results for vocalic durations at this position. The findings correspond to what is expected for French rhythm ([7], [9]) where lengthening of the last syllable of an accentual group is a main rhythmic characteristic in French. Lengthening at subject-final level seems to indicate the presence of an accentual group boundary on this position, while the absence of lengthening at verb-final level indicate a grouping of the verb and its object, putting the two chunks into a unique group with only a final lengthening.

Korean learners produce vocalic lengthening less systematically but more frequently. Rhythm is organized in terms of group weight: They have a tendency to re-segment the utterances in order to obtain a maximum of six/seven syllables per group ([9] among others posit that accentual groups in French contain seven syllables), and to lengthen the end of these new groups, no matter the syntactic description. Moreover, lengthening is less marked for Korean learners than for French speakers. 


\subsubsection{Intonation}

For intonation, we compared the F0 values for the last vowel of each chunk (subject, verb and object). Results show that the two groups (French native speakers and Korean learners of French) produce very close patterns.

Thus, at the end of utterances (i.e. at the end of object phrases), both French and Korean speakers produce massively a HL pattern (utterances $3 \times 2,3 \times 3,3 \times 6,3 \times 8,3 \times 9,3 \times 10$ ), which can be followed by a small rising (utterances $3 \times 2,3 \times 6,3 \times 8$ ). Korean learners have more random productions with more final risings, and even a rising pattern for utterance $3 \times 7$. However, the ANOVA test reveals a non-significant difference for $\mathrm{F} 0$ realizations of the two groups of speakers on the last vowel of the utterance.
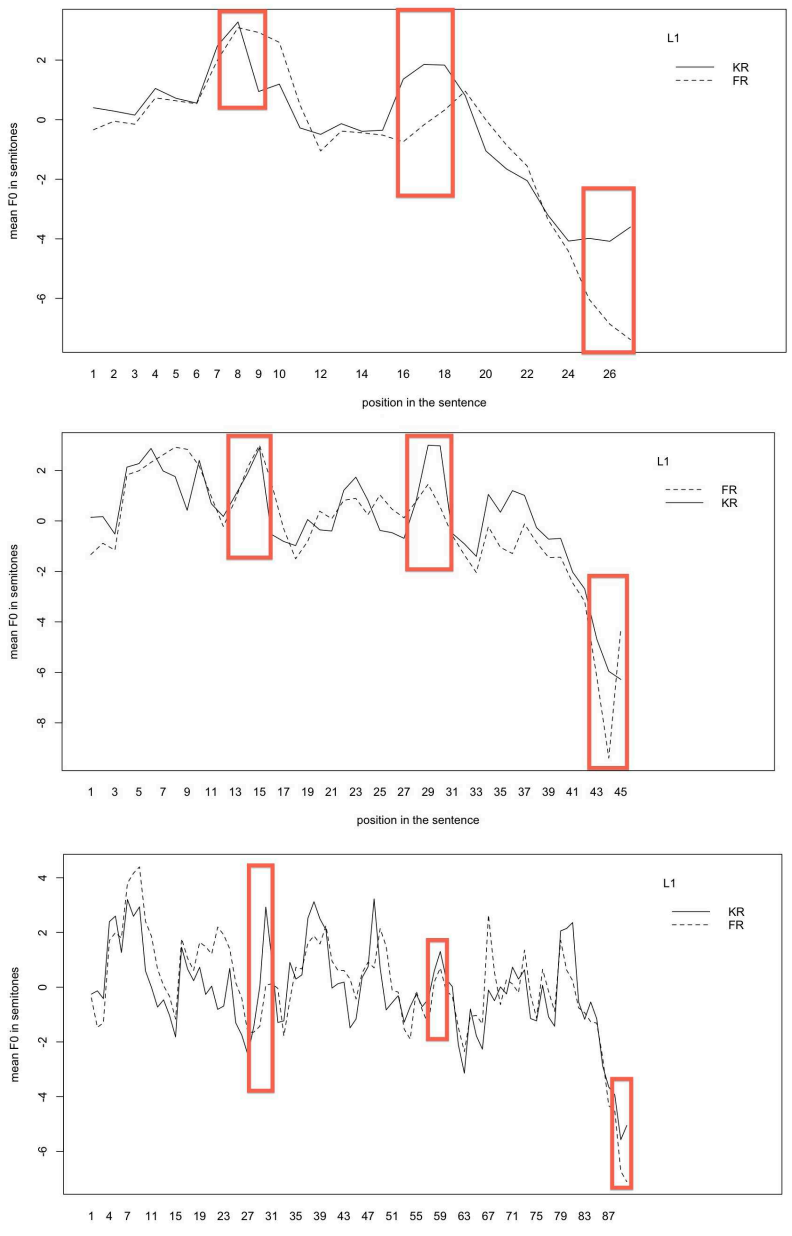$$
\text { pos }
$$

Figure 2: Mean F0 of the two groups for $3 \times 3,3 \times 5$ and $3 \times 10$ syllable utterances.

The F0 realization on the last vowel of the subject is also similar for both groups. However, the type of pattern can vary, with a fall-rise pattern for utterance $3 \times 1$, a rising pattern for utterances $3 \times 5,3 \times 6$ and $3 \times 10$, and a falling pattern for utterance $3 \times 7$. The realizations of the two groups of speakers differ for utterances $3 \times 2,3 \times 3,3 \times 8$ and $3 \times 9$ syllables

Results are less homogeneous at the end of verbs. Within the group of French speakers, the last vowel at this position is produced as a flat pattern in short sentences $(3 \times 1$ and $3 \times 2$ syllables), a rising pattern in utterances $3 \times 3,3 \times 7$ et $3 \times 9$ syllables, a rise-fall pattern in utterances $3 \times 5$ and $3 \times 10$ and a falling pattern in utterances $3 \times 4,3 \times 6$ et $3 \times 8$. Korean learners realize also the same patterns but not for the same utterances: rising pattern is found in utterances $3 \times 3,3 \times 5$ and $3 \times 7$, a flat pattern in utterances $3 \times 1$ and $3 \times 8$, a rise-fall pattern in utterances $3 \times 2,3 \times 9$ and $3 \times 10$, a falling pattern in utterance $3 \times 4$, and a falling pattern followed by a rise in utterances $3 \times 6$. Figure 2 illustrates the differences and similarities of the F0 measures for the two groups of speakers (French L1 and Korean L2 speakers) for three utterances $(3 \times 3=9,3 \times 5=15$ and $3 \times 10=30$ syllables).

Thus, for utterances $3 \times 3$, even though the main shape of the F0 curve is similar for the two groups, the ANOVA test reveal significant results for: 1) the last vowel of the verb (at onset $(\mathrm{F}(1,39)=11,479 \mathrm{p}=.0016)$, at mid-point $(\mathrm{F}(1,56)=10,045$ $\mathrm{p}=.0025)$ and at end-point $(\mathrm{F}(1,44)=9,303 \mathrm{p}=.0039)$ of the vowel) and 2) at end-point of the vowel of the object $(\mathrm{F}(1,33)=5,883 \mathrm{p}=.0209)$.

For utterances $3 \times 5$, the ANOVA test shows that there is a significant difference for the verb (at mid-point $(\mathrm{F}(1,51)=14,255 \mathrm{p}=.0004)$ and at end-point of the final vowel of the verb $(\mathrm{F}(1,40)=13,974 \mathrm{p}=.0006))$ and the object (at midpoint of the final vowel of the object $\mathrm{F}(1,43)=5,453$ $\mathrm{p}=.0243$ ). The ANOVA test is not significant at subject-final level.

For utterances $3 \times 10$, the main F0 shapes are similar for both groups. However, the ANOVA test reveals a significant difference at the subject position (at mid-point $(\mathrm{F}(1,52)=$ $11,827 \mathrm{p}=.0012)$ and at end-point $(\mathrm{F}(1,35)=36,713 \mathrm{p}<.0001)$ on the last vowel of the subject ), mainly because of the more important rise produced by the Korean learners.

For intonation, it appears that overall F0 shape is similar for both Korean learners and French native speakers, but statistical analysis show significant differences in some positions of contour, especially at the end of the verb and at the end of utterances. The F0 contours produced by Korean learners are less systematic and present more variety than those produced by French speakers.

\subsubsection{F0 declination slope}

We used a regression-analysis in order to measure the overall declination slope of the F0 ([18] and [13]). The slopes of the regression line were calculated by taking into account the three F0 values (converted in semi-tones) on the last vowel of each group. Results given in Table 1 show that the two groups have the same attitude in regards to this prosodic characteristic, with an overall progressing F0 declination from the beginning to the end of utterances.

However, results show that the declination slope is slightly more important for French native speakers than Korean learners (the slopes of regression line are always negative, and have a higher absolute value for the French speakers than for the Korean speakers). This observation can also be seen in the study of [2] who noticed that declination slope is less marked in L2 speakers than L1 speakers. Finally, contrarily to what has been observed by [12] for Korean, there is a correlation between the length of the utterances and the declination slope: when the utterance is longer, the declination slope is less steep, but the highest F0 point at the beginning of the utterance and the lowest point and the end of the utterance remain the same, no matter the length of the utterance.

Since the production analyses revealed slight but statistically significant differences between French native speakers and Korean learners, the next step of our procedure was to test if these differences are perceived, and if they represent sufficient 
cues to identify a foreign accent. We present the results of the perception experiment in the next section.

\begin{tabular}{|l|l|l|}
\hline $\begin{array}{l}\text { Number of } \\
\text { syllables per } \\
\text { chunk }\end{array}$ & $\begin{array}{l}\text { Slopes of regression } \\
\text { line for French } \\
\text { speakers }\end{array}$ & $\begin{array}{l}\text { Slopes of regression } \\
\text { line for Korean } \\
\text { learners }\end{array}$ \\
\hline 1 & $-1,201$ & $-0,722$ \\
\hline 2 & $-0,393$ & $-0,377$ \\
\hline 3 & $-0,228$ & $-0,187$ \\
\hline 4 & $-0,116$ & $-0,110$ \\
\hline 5 & $-0,112$ & $-0,080$ \\
\hline 6 & $-0,980$ & $-0,690$ \\
\hline 7 & $-0,940$ & $-0,048$ \\
\hline 8 & $-0,055$ & $-0,032$ \\
\hline 9 & $-0,054$ & $-0,029$ \\
\hline 10 & $-0,036$ & $-0,025$ \\
\hline
\end{tabular}

Table 1: Slopes of regression line for all utterances and for the two groups of speakers (French an Korean)

\section{Perception}

Since the production experiment showed only slight differences in production in French by French and Korean speakers both for rhythm (vocalic durations) and intonation (F0 contours and declination lines), we expect that these differences in the Korean speakers' production at a prosodic level are not sufficient enough to be perceived by naive French listeners as a «foreign accent» in comparison to the French speakers' production. In this section we present the results of a pilot experiment built to test the perception of this "accent".

\subsection{Experimental procedure}

The perception experiment is built in three different conditions. First, we neutralized segmental information: we synthesized the intonation and rhythm of two French and two Korean speakers who participated at the production experiment with the voice of a French native speaker, which allowed us keeping segmental information but changing the prosodic profile of the utterances (we thus obtained synthesized sentences with different prosodic profiles on a same French voice). Second, segmental and rhythmic information have been neutralized: thus, we coupled a long /a/ sound with the intonational tier of the four speakers used in the first condition while rhythm is neutralized for all syllables: in this test, we chose to keep only part of the initial stimuli $(3 \times 4$, $3 \times 6$ and $3 \times 8$ syllables were not used) since the listening task of utterances with no segmental information is quite difficult to perform for naïve listeners. The third test is the control condition: stimuli remain unmodified productions of the same speakers, without any manipulation of segmental information, rhythm and intonation. The perception experiment is created and run on Praat [16]. Eight native speakers of French took part in the experiment which was conducted on a laptop and using headphones. The experiment is a forced choice task in which they are asked to judge if the stimulus is pronounced by a speaker with a foreign accent or by a French native speaker.

\subsection{Results and discussion}

When segmental information has been neutralized and only rhythm and intonation remain (test 1 of Tables 2 and 3), answers for "foreign accent" are only slightly above chance (62.5 to 67.2\%) for shorter sentences (1 to 3 syllables per group). Results gradually improve for longer sentences (4 to 9 syllables per group) and reach $87.5 \%$ for "foreign accent".
When only the parameter of intonation is kept as the only cue, results for shorter sentences are low (42.2 to $54.7 \%$ for "foreign accent"), improve when sentences are longer (5 and 7 syllables per group) but remain around average for the longest tested sentences ( 9 syllables per group). The analyses of answers chosen per stimulus show that listeners identify the stimuli of native speakers of French correctly in only $42.7 \%$ of cases, which indicate that in this test, choices are made randomly.

In the control condition (Test 3 of Tables 2 and 3), results are as expected for all types of sentences (above 95.3\%): segmental variation has not been analyzed in this study, yet it seems to be strong enough for the listeners to identify a foreign accent.

\begin{tabular}{|l|l|l|l|}
\hline Number of $\begin{array}{l}\mid 3 \\
\text { syllables in } \\
\text { the sentence }\end{array}$ & Test 1 & Test 2 & Test 3 \\
\hline $3 \times 1=3$ & $62,5 \%$ & $53,1 \%$ & $100 \%$ \\
\hline $3 \times 2=6$ & $67,2 \%$ & $42,2 \%$ & $98,9 \%$ \\
\hline $3 \times 3=9$ & $62,5 \%$ & $54,7 \%$ & $95,3 \%$ \\
\hline $3 \times 4=12$ & $82,8 \%$ & - & $98,4 \%$ \\
\hline $3 \times 5=15$ & $78,1 \%$ & $67,2 \%$ & $100 \%$ \\
\hline $3 \times 6=18$ & $73,4 \%$ & - & $96,9 \%$ \\
\hline $3 \times 7=21$ & $79,7 \%$ & $60,9 \%$ & $96,9 \%$ \\
\hline $3 \times 8=24$ & $87,5 \%$ & - & $100 \%$ \\
\hline $3 \times 9=27$ & $87,5 \%$ & $50 \%$ & $87,5 \%$ \\
\hline
\end{tabular}

Table 2: Percent of answers for "foreign accent" for the three conditions for each utterance (1/L2 rhythm and intonation, 2/Intonation only, 3/ no modification)

\begin{tabular}{|l|l|c|c|}
\hline & \multicolumn{2}{|c|}{} & \multicolumn{2}{|c|}{ Stimulus produced by } \\
\hline \multirow{2}{*}{$\begin{array}{l}\text { Answers } \\
\text { for Test 1 }\end{array}$} & $\begin{array}{l}\text { French speaker's } \\
\text { production }\end{array}$ & $82,6 \%$ & $\begin{array}{l}\text { Korean } \\
\text { speaker }\end{array}$ \\
\cline { 2 - 4 } & Foreign Accent & $17,4 \%$ & $68,7 \%$ \\
\hline $\begin{array}{l}\text { Answers } \\
\text { for Test 2 }\end{array}$ & $\begin{array}{l}\text { French speaker's } \\
\text { production }\end{array}$ & $42,7 \%$ & $33,3 \%$ \\
\cline { 2 - 4 } & Foreign Accent & $57,3 \%$ & $66,7 \%$ \\
\hline $\begin{array}{l}\text { Answers } \\
\text { for Test 3 }\end{array}$ & $\begin{array}{l}\text { French speaker's } \\
\text { production }\end{array}$ & $95,5 \%$ & $1,7 \%$ \\
\cline { 2 - 4 } & Foreign Accent & $4,5 \%$ & $98,3 \%$ \\
\hline
\end{tabular}

Table 3: Results sorted by types of stimuli (produced by French or Korean speaker)

\section{Conclusion}

The production experiment showed that as far as rhythm is concerned, Korean learners of French tend to change boundaries and to lengthen the end of these groups, no matter the syntactic structure. Otherwise, strategies for intonation and declination slope are quite similar for both language groups.

This pilot perception experiment gives a first indication of the difficulty for native listeners to clearly perceive slight, randomly distributed differences in the production of L2 learners of French. It also reveals that the identification of "foreign accent" is easier when utterances are longer. This result is consistent with [3]'s results on German and USEnglish production and perception. It appears that the perception of a "foreign accent" is linked to prosodic proximity of the two tested languages. Ongoing work includes more listeners but also the dissociation between the two main parameters, rhythm and intonation. Moreover, a further production and perception study with the same material in French with speakers of a typologically different language could help understanding and confirming our findings. 


\section{References ${ }^{\mathrm{i}}$}

[1] Flege, J., 1995, "Second Language Speech Learning: Theory, Findings, and Problems". In W. Strange (Ed.), Speech Perception and Linguistic Experience: Issues in Cross-Language Research (pp. 233 - 272). Timonium, MD: York Press

[2] Mennen, I., 2007. "Phonological and Phonetic Influences in Non-native Intonation”, In J. Trouvain and U. Gut (Eds.): NonNative Prosody - Phonetic Description and Teaching Practice. Mouton De Gruyter, Berlin, pp 53-76

[3] Jilka, M., 2007, "Different Manifestations and Perceptions of Foreign Accent in Intonation", in J. Trouvain and U. Gut (Eds.) Non-Native Prosody - Phonetic Description and Teaching Practice. Mouton De Gruyter, Berlin, pp. 77 - 96

[4] Barry, W.J., 2007. "Rhythm as an L2 Problem: How prosodic is it?" In J. Trouvain and U. Gut (Eds.): Non-Native Prosody Phonetic Description and Teaching Practice. Mouton De Gruyter, Berlin, pp 97-120

[5] Piske T., MacKay, I.R.A, Flege, J.E, 2001, "Factors affecting degree of foreign accent in an L2: a review? Journal of Phonetics 29:191-215

[6] Vaissière, J. \& Boula de Mareüil, 2004."Identifying a language or an accent: from segment to prosody, in Proceedings of the Modelling for the Identification of Languages (MIDL) Workshop, Partis 1-6

[7] Di Cristo, A., 1999, "Intonation in French". In Daniel Hirst and Albert Di Cristo (eds), Intonation Systems: A Survey of Twenty Languages. Cambridge: Cambridge University Press

[8] Jun, S.-A., 1993, "The Phonetics and Phonology of Korean Prosody", PhD Dissertation, Ohio State University

[9] Martin, P., 2009, "Intonation du Français", Paris, Armand Colin

[10] Lee, H.-Y., 1990, "The structure of Korean Prosody", PhD Dissertation, University College of London

[11] Delattre, P., 1966, "Les dix Intonations de Base du Français", French Review 40, p1-14

[12] Ko, D-H., 1988, Declarative Intonation in Korean: An Acoustical Study of F(o) Declination, Ph.D. Thesis, U. of Kansas

[13] Schmid, C. Gendrot, C., \& M. Adda-Decker. 2012. "Une comparaison de la déclinaison de F0 entre le français et l'allemand journalistiques" Actes des 28èmes Journée d'Etude sur la Parole, Grenoble, France, 4-8 juin 2012, pp. 329-336.

[14] Audacity Version2.0, retrieved 01 November 2013 from http://audacity.sourceforge.net

[15] Goldman J.-Ph. 2011. «EasyAlign: an automatic phonetic alignment tool under Praat» in Proceedings of InterSpeech, September 2011, Firenze, Italy

[16] Boersma, P. \& Weenink, D., 2013. "Praat: doing phonetics by computer" [Computer program]. Version 5.3.59, retrieved 20 November 2013 from http://www .praat.org/

[17] R Development Core Team (2012). R: A language and environment for statistical computing. R, Foundation for Statistical Computing, Vienna, Austria. ISBN 3-900051-07-0, URL http://www.R-project.org/.

[18] Lieberman P. et al., 1985. "Measures of the sentence intonation of read and spontaneous speech in American English" Journal of the Acoustical Society of America 77, 649-657.

${ }^{\mathrm{i}}$ This work is supported by a public grant overseen by the French National Research Agency (ANR) as part of the "Investissements d'Avenir"-Labex EFL program (reference: ANR-10-LABX-0083) 